\title{
The Rainbow Reading Programme: A Review 20 years on
}

\author{
Emma Dobson
}

RTLB Practice Leader, Auckland West Cluster

\begin{abstract}
It has been 20 years since the Rainbow Reading programme was developed and trialled by its New Zealand creator, Meryl-Lynn Pluck. Rainbow Reading is an audio-facilitated reading programme, and is based on the method of assisted repeated reading. The programme is designed to provide older students reading below their chronological age with the opportunity to practise their fluency and comprehension at their instructional reading level. This article sets out to review the programme, drawing on the research evidence to evaluate Rainbow Reading's validity and reliability as a reading intervention for use by educational practitioners in the New Zealand education context. Possible strengths and limitations of the programme are identified, and future directions for the programme are put forward. While the article concludes by suggesting some caution with regard to its use, it is evident that the effectiveness of an intervention such as Rainbow Reading is underpinned by practitioners taking an evidence-based approach in their professional practice.
\end{abstract}

\section{Research Paper}

Keywords: Audio-facilitated reading, evidence-based intervention, Rainbow Reading, repeated reading

\section{INTRODUCTION}

This year signifies the twentieth anniversary of when the Rainbow Reading programme was first developed and trialled in $1993^{1}$ by its creator, Meryl-Lynn Pluck, a Resource Teacher of Reading (RTR) from the Nelson region of New Zealand (Pluck, 1995). Based on the technique of assisted repeated reading, Rainbow Reading is an audio-facilitated reading programme. According to Pluck $(1995 ; 2006)$ the programme was developed in response to the significant number of referrals received by the RTR in Nelson from schools requesting assistance for students who were underachieving in reading. As Pluck (2006) states, the programme "would need to reach readers at a 'rainbow' of levels" (p.193); hence its name - Rainbow Reading Programme.

Given this 20 year milestone, it is therefore timely to review the programme, and to evaluate its validity and reliability as a reading intervention for use by educational practitioners with students in New Zealand schools. In order to undertake this review, the article first provides an outline of how the Rainbow Reading programme is used in the school setting, including its purpose and relationship to key government documents, such as The New Zealand Curriculum and Success for All - Every School, Every Child (Ministry of Education (MOE), 2007; 2010a). The article then investigates the evidence base that underpins the programme through examining relevant theory and research, before moving on to discuss the expected outcomes for students using the programme. This discussion provides the context for identifying possible strengths and limitations of it. The article concludes by addressing the question of 'Where to next?' for Rainbow Reading, considering future directions for the programme.

\section{What is Rainbow Reading? Its Purpose and Use}

The Rainbow Reading programme is divided into eight colour-coded levels, ranging from the Silver Level (reading age of $5-5.5$ years) through to the Purple Level (reading age of 11-12 years). Each level contains a set of 20 books, with each book accompanied by an audio CD or MP3 audio file of the text, and text-related activities, such as cloze (text completion), word search and writing activities (Rainbow Reading Programme Ltd., 2013a).

The purpose of the programme is to meet the needs and interests of older, struggling readers at the primary, intermediate and early secondary school levels through providing them with the opportunity to practise their reading fluency and comprehension at their instructional reading level, thus developing the

The Rainbow Reading programme has been commercially available in New Zealand since 1995 (Nalder, 2002). 
confidence and skills to enable them to progress to higher reading levels (Langford, 2001; Pluck, 1995; 2002). While the programme can also be used with students from non-English speaking backgrounds and those receiving Reading Recovery (Pluck, 2002), it is clear that the programme is not intended for use with students in the foundation years of schooling. This is because students on the programme need to have attained a certain level of basic literacy skills, including recognising the letters of the alphabet and their corresponding sounds, basic high-frequency words and concepts about print (Rainbow Reading Programme Ltd., 2013b).

Rainbow Reading is designed to complement (rather than replace) existing class reading programmes, and is "most effective when introduced as part of the regular reading programme" (Pluck, 2002, p.5). Dowhower (1994) argued that such assisted repeated reading techniques should not be used in isolation, but integrated into daily literacy instruction. However, according to Pluck (2002) a teacher-aide can also manage a group of students using the programme by withdrawing them from their classroom for daily practice or supervising them within their classroom. This raises the issue of the extent to which the programme facilitates inclusion in the classroom environment.

In order to support the implementation of the Rainbow Reading programme, a teacher's manual and training DVD are available. However, there are three factors educational practitioners need to address before implementing the programme - identifying how the programme will be organised (i.e. integrated as part of the class reading programme or used as withdrawal); setting up a box for each level that contains the necessary equipment and materials (e.g. CD players, headphones, batteries, books, audio CDs, text-related activities), and establishing the student's starting level on the programme (Pluck, 2002). Once these factors have been addressed, there are four steps involved in running the programme: 1 . 'orientation' of the book with the tutor (i.e. teacher or teacher-aide); 2. 'reading practice' using the book and audio CD; 3. 'reading alone' with the book; 4. 'conferencing' with the tutor (Pluck, 2002). Depending on the outcome of the conference, the process begins again with a new book at the student's level. It is recommended that students practise on the programme for 30 minutes five times a week, for approximately ten weeks (Pluck, 2002).

While Rainbow Reading was developed nearly 15 years prior to the current primary and secondary school curriculum, the programme remains relevant to The New Zealand Curriculum document in two areas (MOE, 2007). The first area is that of the key competencies such as 'using language, symbols and texts' and 'managing self' (MOE, 2007). Pluck (2006) believes that the programme aims to foster independence through allowing students to make decisions with regard to their reading, such as when to 'read alone' or to 'have a conference'. This relates to the key competency of 'managing self', which is associated with self-motivation and students seeing themselves as capable learners (MOE, 2007). Such a view also aligns with the Government's Success for All - Every School, Every Child, whereby the vision is to "foster confident children", (MOE, 2010a, p.1). with schools and teachers understanding that students learn at different rates. However, at a deeper level, the Rainbow Reading programme could be seen to be in conflict with Success for All's plan to "achieve a fully inclusive education system" (MOE, 2010a, p.1), as the issue has been raised of the extent to which the programme promotes an inclusive learning environment.

The second is the learning area of English (MOE, 2007). According to The New Zealand Curriculum, through engaging with text-based activities, students become increasingly skilled and sophisticated speakers and listeners, writers and readers, presenters and viewers (MOE, 2007). In effect, the Rainbow Reading programme supports this aim of the English curriculum through the students listening to books on audio CDs, viewing the illustrations and text features in the books, reading the books independently or to a tutor, and undertaking text-related activities.

Further to the curriculum, the programme also links in with The Literacy Learning Progressions (MOE, 2010b). The progressions alert teachers to what students need to know and be able to do in reading and writing at specific points in their schooling from Years 1 - 8 (MOE, 2010b). Through using the progressions to monitor student progress in reading, Rainbow Reading could be employed as a preventative intervention. As Nalder (2002) advocates, a programme such as Rainbow Reading should be used not for remediation once students have fallen notably behind their peers, but rather for the prevention of reading difficulty. Such an argument sits within the Response-to-Intervention (RTI) model, which Reynolds, Wheldall and Madelaine (2011) perceive as a preventative approach in relation to reading difficulties. Tunmer and Greaney (2010) also recognise that an RTI model can be used as the basis for providing differentiated instruction to improve the educational outcomes for at-risk readers.

\section{Where does Rainbow Reading come from? The Evidence Base}

The Rainbow Reading programme is embedded in 
constructivism whereby students play an active role in their learning and, more specifically, draws on Vygotsky's Zone of Proximal Development (ZPD) (Eggen \& Kauchak, 1999). The technique upon which the programme is based, that of assisted repeated reading, allows students to work within their ZPD and provides the scaffolding that enables them to successfully move beyond the point at which they are able to work independently (Kuhn \& Stahl, 2000). In this respect, students are scaffolded in their reading through listening to a book on a $C D$ at their instructional reading level, before deciding that they are able to read the book well without audio support and to have a conference with their tutor (Pluck, 2002).

Assisted repeated reading is a form of repeated reading which is a method that emerged out of automaticity theory (Dowhower, 1994; LaBerge \& Samuels, 1974, cited in Samuels, 1997). According to Samuels (1997), automaticity theory is when a fluent reader decodes text automatically, "leaving attention free to be used for comprehension" (p.379). However, automaticity theory does not attend to reading with expression and phrasing, which Kuhn and Stahl (2000) argue is an important aspect of reading fluency. Developing fluency requires practice, which "is where a technique such as assisted repeated reading comes in" (Rasinski, 2004, p.48). It is repeated reading with a model - this model can be an adult, a more proficient peer, or an audio CD (Chard, Vaughn \& Tyler, 2002). However, there has been debate as to the effectiveness of assisted repeated reading that is audio-facilitated. In their meta-analysis of research on interventions for building reading fluency with students, Chard et al. (2002) state that repeated reading with a model is more effective than repeated reading with no model, but that audio-facilitated reading is not as effective as using an adult as a model. Such a view had already been espoused by Dowhower (1994), who argued that assisted repeated reading techniques that involve a student silently reading a text while listening to an audio CD do little to increase their overall fluency and comprehension. Yet, as Bircham, Shaw and Robertson (1997) identified, research conducted in the way of controlled studies demonstrating the efficacy of audio-facilitated reading programmes was limited.

In their review of research on fluency instruction, Kuhn and Stahl (2000) identified research by Chomsky in 1976 as the first to demonstrate measurable gains using audiotapes for assisted repeated reading. After ten months of working with five 8-year old students identified as reading below their chronological age, Chomsky found the students averaged a six-month gain in fluency and 7.5 month gain in comprehension (Kuhn \& Stahl, 2000). In a different audiotape-based study, Carbo in 1981 worked with eight 'learning disabled' students in reading over a period of three months, and reported that the students demonstrated an average gain of eight months in their reading ability (Kuhn \& Stahl, 2000). A further study by Shany and Biemiller (1995) of 29 third- and fourth-grade 'poor readers', which took place in Canada over a 16-week period, involved the students being divided into three groups: two experimental groups - one received practice in reading with teacher assistance and the other received practice while listening to an audiotape; and a control group - these students only received regular classroom reading instruction (Shany \& Biemiller, 1995). The results showed that gains in reading fluency and comprehension in the experimental groups exceeded those in the control group, and that the group that practiced using an audiotape also had higher scores on listening comprehension (Shany \& Biemiller, 1995). Such results are supported by Bircham et al., (1997) who, in their study of 27 eight to nine year old students in Scotland, found that using audio-facilitated reading was "as effective as teacherled language-based activities" (p.184).

While the above research studies have been conducted in North America and the United Kingdom, in the New Zealand education context, a study was undertaken prior to the development of Rainbow Reading that compared an audio-facilitated reading programme with peer tutoring using the Pause Prompt Praise technique (Medcalf, 1989). The study took place over eight weeks and involved ten 'low progress readers' ranging in age from 9 11 years. The average gain for students using the audio-facilitated reading programme was 1.4 years, while the average gain for tutors and tutees on the peer tutoring programme was 2.5 years. However, those using the audio-facilitated programme made the greatest gains during the follow-up phase at six weeks, with an additional gain of nine months compared to two months for the students on the peer tutoring programme (Medcalf, 1989).

\section{What are the Expected Outcomes for Students? Possible Strengths and Limitations}

The expected outcomes of the Rainbow Reading programme are to raise students' instructional reading age and, more specifically, to improve students' reading accuracy, fluency and comprehension of practiced texts (Nalder, 2002; Nalder \& Elley, 2003). ${ }^{2}$

A total of four ${ }^{3}$ research studies have been undertaken on the programme within the New Zealand education context (Langford, 2001; Nalder, 2002; Nalder \& 
Elley, 2003; Piper, 2009; Pluck, 1995), while three studies have been conducted overseas - in Australia ${ }^{4}$ America and the United Kingdom (Lesnick, 2006; McGraw Hill School Education Group, 2012; Wheldall, 2000). All of the New Zealand studies, as well as the overseas case study undertaken in the United Kingdom, showed that the majority of students using the programme made positive gains in their reading age (Langford, 2001; McGraw Hill School Education Group, 2012; Nalder, 2002; Nalder \& Elley, 2003; Piper, 2009; Pluck, 1995). For example, Pluck (1995) reported average gains from 2.2 to 4 years in reading age, Langford (2001) recorded an average gain of 1.2 years per student, while Nalder (2002) and Nalder and Elley (2003) reported gains of 2.2 years. However, such results should be treated with caution because as Kuhn and Stahl (2000) point out in their review of research on fluency instruction, while students may be "ahead of where they started" (p.9-10), they could still be behind in reading for their age. In this respect, the overseas studies undertaken in Australia and America, which both used control groups, found that the programme did not add value to an existing intensive literacy intervention programme (Wheldall, 2000), and had no significant impact on student fluency and comprehension (Lesnick, 2006).

However, of concern is the evidence encountered to support the effectiveness of the Rainbow Reading programme, which could be questioned in terms of its validity and reliability. None of the New Zealand research studies used control groups to measure the effectiveness of the programme objectively, and they also involved small groups of students (from 10 to 43), across a range of year levels (from Years 2 to 10) The length of these studies also varied, ranging from 8 to 32 weeks, and the extent to which the expected outcomes for students can be attributed solely to the programme is tenuous as the New Zealand studies did not consider the impact of the students' regular in-class reading programme in relation to the Rainbow Reading programme. Moreover, all the studies undertaken on the programme in the New Zealand education context used Rainbow Reading in a withdrawal model, which brings into question, as mentioned previously, the inclusive nature of the programme (Langford, 2001; Nalder, 2002; Nalder \& Elley, 2003; Piper, 2009; Pluck, 1995). Thus, it is how the Rainbow Reading programme is implemented that will illustrate whether it facilitates inclusion.

Needless to say, there are both strengths and limitations to the Rainbow Reading programme. One of the main strengths is that it scaffolds students in their reading, supporting them to move through the ZPD. This is because the programme is based on the technique of assisted repeated reading which enables the student to attend to different aspects of the text during each re-reading, such as word accuracy, expression or comprehension, thus increasing student control over the text and fostering fluency, comprehension and confidence (Pluck, 2002).

The programme is also learner-centred and encourages student independence (i.e. the key competency of 'managing self') through enabling students to retain an element of ownership over their reading and learning (Pluck, 2006). The programme allows students to make decisions with regard to their reading, such as when to 'read alone' or to 'have a conference'.

Moreover, the content of the books is a mix of fiction and non-fiction and covers a wide variety of topics/ themes in order to maintain student interest, particularly the interests of older students (Pluck, 2002). As Abadiano and Turner (2005) argue, student motivation and the type of materials used to motivate repetitive readings "play a prominent role in developing fluency" (p.55).

A final strength of the programme is that it is produced in New Zealand and, as such, not only links in with The New Zealand Curriculum (MOE, 2007), but the materials developed use New Zealand voices on the audio CDs and topics/illustrations relevant to New Zealand society (Pluck, 2006). However, this final point should be treated with caution, as it raises the issue of what does this New Zealand society 'look like', including whose beliefs and values are represented and whose interests are being served.

One of the most significant limitations of the programme is that it is expensive to purchase. While the programme is reusable, the cost of purchasing a set of 20 books and 20 audio CDs in a display box is NZ\$430 (including GST) per level (Rainbow Reading Programme Ltd., 2013a). Hypothetically, a full primary (Years 1-8) may potentially need to purchase at least six levels, which is an initial total cost of NZ\$2580 (including GST). However this price excludes CD players, headphones and batteries, which would also need to be purchased in order to implement the programme effectively. Moreover, there is the cost involved in maintaining the programme, such as replacing damaged books, and if a school chooses to employ a teacher-aide to run the

\footnotetext{
${ }^{2}$ Nalder (2002) and Nalder and Elley (2003) are readings on the same research study conducted on the Rainbow Reading programme in New Zealand. Their study was later published in Reading Forum NZ in 2004 (Pluck, 2006).

${ }^{3}$ Pluck (2006, p.199-200) refers to a study on the Rainbow Reading programme that was undertaken in 2001 at an intermediate school in Dunedin. However, this study is unpublished, and the decision has therefore been made not to include this study in the article.

4 The American study is of the New Heights programme, which is the American version of the Rainbow Reading programme (Lesnick, 2006).
} 
programme, this can be a further ongoing cost.

While it has been previously suggested, as Nalder (2002) recommends, that the programme should be used for the prevention of reading difficulty rather than as a form of remediation, Rainbow Reading is essentially a remediation programme. This is because the programme centres on addressing students' deficits in reading through focusing on meeting the needs and interests of older struggling readers, rather than acknowledging their strengths (Pluck, 2002). Thus it could be argued that competing methodologies underpin the programme - emphasising students' deficits in reading on the one hand, while providing differentiated instruction on the other, through students having modified access to materials that are consistent with their learning needs in reading (Broderick, Mehta-Parekh \& Reid, 2005).

A further limitation of the Rainbow Reading programme is that there is no research evidence regarding the extent to which the programme is culturally-responsive, not only to the needs of Maori students in mainstream New Zealand schools ${ }^{5}$, but also to the needs of Pasifika students and students from other cultural groups. Consideration should therefore be given to whether the theories and research that underpin the programme pedagogically support teaching and learning in reading for these students. The programme would need to focus on promoting a culturally-responsive pedagogy, aligning to the students' cultural beliefs, values and preferences. As Ladson-Billings (1995, cited in Wearmouth, Glynn \& Berryman, 2005) argues, educational programmes should be adapted to the student, rather than making the student ' $\mathrm{fit}^{\prime}$ the programme.

Finally, while research studies have been undertaken on the Rainbow Reading programme both in New Zealand and overseas, there is variation in how these studies have been conducted. This has raised the issues of the validity and reliability of the outcomes reported and the effectiveness of the programme in improving students' instructional reading age.

\section{Where to Next? Considerations for the Future}

One of the primary considerations for the future is that the effectiveness of the Rainbow Reading programme within the New Zealand education context needs to be investigated more thoroughly. This involves robust, independent and controlled research studies of the programme undertaken across different levels of the compulsory school sector. Results should be published in internationally refereed journals in order to illustrate the validity of the research and extend the programme's evidence base.

It is also important that the cost of purchasing the programme remain economically viable in order that schools and students from a diverse range of contexts (e.g. small/large schools, schools in rural/ urban locations, low/high decile schools) can access the programme. The option of purchasing a disc of $20 \mathrm{MP} 3$ audio files to accompany the books at each level is available for $\$ 185$ (including GST - as opposed to a set of 20 audio CDs for $\$ 240$ per level), which raises the issue of whether these files could be downloaded directly from the Rainbow Reading website in order to reduce costs further (Rainbow Reading Programme Ltd., 2013a).

Finally, consideration needs to be given to how the programme is implemented so that it is not used solely as a withdrawal programme for those students who are reading below their chronological age. The process for implementing the programme should address whether it can be effectively integrated into existing class reading programmes by teachers in a way that is ecological and promotes inclusion.

This raises the issue of whether it is possible to incorporate a form of peer tutoring into the Rainbow Reading programme, adapting the programme so that students are trained in the role of 'tutor'. The programme draws on the same technique at the conferencing step of the process that Medcalf (1989) used in his comparative research study, that of Pause Prompt Praise (Medcalf, 1989; Pluck, 2002). Perceived as an inclusive educational practice, peer tutoring is effective in increasing the academic achievement and social interactions of a diverse range of students (Medcalf, Glynn \& Moore, 2004; Mitchell, 2008).

\section{CONCLUSION}

Through undertaking this review of the Rainbow Reading programme 20 years on, which has involved considering its strengths, limitations and future directions, it could be argued that its use, as with any educational intervention, should be treated with some caution. This is because the article has raised concerns regarding the 'robustness' of the research conducted on the programme, the extent to which it promotes inclusion, and the financial cost of the programme.

\footnotetext{
${ }_{5}$ From 2003-2005, Meryl-Lynn Pluck worked with Learning Media to develop Te Huinga Raukura - an audio-facilitated programme based on the same formula as Rainbow Reading, and designed for use with students in Maori-medium schools and Maori-immersion classes who are learning to read, write and speak in Maori (The Nelson Mail, 2004).
} 
While Rainbow Reading can be used with older students at the primary, intermediate and early secondary school levels who are reading below their chronological age, it is the students' needs that should be primarily taken into account. Thus, educational practitioners need to consider why they are choosing to use this programme - What purpose will it serve?; Do they believe that the programme will help facilitate achievement of the goals planned for the student(s) concerned? As Annan (2005) argues, practitioners cannot simply determine the applicability of an intervention by attempting to match it to a context in which the intervention may have previously been successful. The decision of whether to use an intervention such as Rainbow Reading should be based on integrating best evidence with practitioners' professional knowledge and judgement, and with the preferences and needs of the student(s).

\section{REFERENCES}

Abadiano, H., \& Turner, J. (2005). Reading fluency: The road to developing efficient and effective readers. The New England Reading Association Journal, 41(1), 50-56.

Annan, J. (2005). Situational analysis: A framework for evidence-based practice. School Psychology International, 26(2), 131-146.

Bircham, A., Shaw, M., \& Robertson, A. (1997). Enhancing reading development using audiotaped books. Educational Psychology in Practice: Theory, Research and Practice in Educational Psychology, 13(3), 181-187.

Broderick, A., Mehta-Parekh, H., \& Reid, D. (2005). Differentiating instruction for disabled students in inclusive classrooms. Theory into Practice, 44(3), 194-202.

Chard, D., Vaughn, S., \& Tyler, B. (2002). A synthesis of research on effective interventions for building reading fluency with elementary students with learning disabilities. Journal of Learning Disabilities, 35(5), 386-406.

Dowhower, S. (1994). Repeated reading revisited: Research into practice. Reading and Writing Quarterly: Overcoming Learning Difficulties, 10(4), 343-358.

Eggen, P., \& Kauchak, D. (1999). Educational psychology: Windows on classrooms. Fourth Edition. New Jersey, USA: Merrill Prentice Hall.
Kuhn, M., \& Stahl, S. (2000). Fluency: A review of developmental and remedial practice. University of Michigan, USA: Centre for the Improvement of Early Reading Achievement. Retrieved October 2012 from http://www.ciera.org/library/reports/ inquiry-2/2-008/2-008.pdf

Langford, J. (2001). 'Tape assisted repeated reading' for a group of low progress readers in a secondary school. Reading Today for Tomorrow, 1421. Retrieved January 2013 from http://www. rainbowreading.co.nz/assets/files/cms/langford.pdf

Lesnick, J. (2006). A mixed-method multi-level randomized evaluation of the implementation and impact of an audio-assisted reading program for struggling readers. Unpublished dissertation. University of Pennsylvania, USA. Abstract retrieved January 2013 from http://repository. upenn.edu/dissertations/AAl3211103/

McGraw Hill School Education Group. (2012). Cardiff Schools: Rainbow reading case study. United Kingdom: McGraw Hill Kingscourt. Retrieved October 2012 from http://specialistteaching. net.nz/file.php/17/moddata/forum/334/15730/ Rainbow_Reading_Case_Study_Jan_2012 _Cardiff_Schools.pdf

Medcalf, J. (1989). Comparison of peer tutored remedial reading using the pause, prompt and praise procedure with an individualised tape-assisted reading programme. Educational Psychology: An International Journal of Experimental Educational Psychology, 9(3), 252262.

Medcalf, J., Glynn, T., \& Moore, D. (2004). Peer tutoring in writing: A school systems approach. Educational Psychology in Practice, 20(2), 157 178.

Ministry of Education. (2007). The New Zealand Curriculum. Wellington: Learning Media Limited.

Ministry of Education. (2010a). Fact Sheet: Success for All - Every School, Every Child. Retrieved January 2013 from http://www.minedu.govt.nz/ /media/ MinEdu/Files/TheMinistry/Educationlnitiatives/ FactSheetSuccessForAll.pdf

Ministry of Education. (2010b). The literacy learning progressions: Meeting the reading and writing demands of the curriculum. Wellington: Learning Media.

Mitchell, D. (2008). What really works in special and inclusive education: Using evidence-based teaching strategies. London: Routledge. 
Nalder, S. (2002). The effectiveness of rainbow reading: An audio-assisted reading program. Retrieved January 2013 from http://www. rainbowreading.co.nz/assets/files/cms/ effectiveness.pdf

Nalder, S., \& Elley, W. (2003). Using Audio-taped readalong stories with low-progress readers. Later published in Reading Forum NZ, 2004, 19(1). Retrieved January 2013 from http:// www.rainbowreading.co.nz/assets/files/cms/ elleyandnalderpdf.pdf

Piper, M. (2009). Rainbow reading study - St Therese School. Unpublished document. Retrieved January 2013 from http://www.rainbowreading.co.nz/ assets/files/cms/es/sttherese.pdf

Pluck, M. (1995). Rainbow reading programme; Using taped stories: The Nelson Project. Reading Forum $N Z, 1,25-30$.

Pluck, M. (2002). Rainbow Reading Programme Teachers' Manual. Nelson, NZ: Rainbow Reading Programme Ltd.

Pluck, M. (2006). "Jonathon is 11 but reads like a struggling 7-year-old": Providing assistance for struggling readers with a tape-assisted reading program. In T. Rasinski, C. Blachowicz and K. Lems (Eds.), Fluency Instruction: Research-Based Best Practices (pp 192-208). New York: The Guilford Press.

Rainbow Reading Programme Ltd. (2013a). Rainbow Reading. Retrieved January 2013 from http://www. rainbowreading.co.nz/products/rainbow_reading

Rainbow Reading Programme Ltd. (2013b). News. Retrieved January 2013 from http://www. rainbowreading.co.nz/news/

Rasinski, T. (2004). Creating fluent readers. Educational Leadership, 61(6), 46-51.

Reynolds, M., Wheldall, K., \& Madelaine, A. (2011). What reviews tell us about the efficacy of reading interventions for struggling readers in the early years of schooling. International Journal of Disability, Development and Education, 58(3), 257-286.

Samuels, S. (1997). The method of repeated readings. The Reading Teacher, 50(5), 376-381.

Shany, M., \& Biemiller, A. (1995). Assisted reading practice: Effects on performance for poor readers in grades 3 and 4. Reading Research Quarterly, 30(3), 382-395.

The Nelson Mail. (2004, 11 March). Learning Maori made easier. Retrieved October 2012 from http:// ehis.ebscohost.com.ezproxy.massey.ac.nz/eds/de tail? $v$ vid $=3 \&$ hid $=103 \&$ sid $=6$ bf7bbec-e $431-4575$ 840e-ea76b163e5f1\%40sessionmgr104\&bdata=1

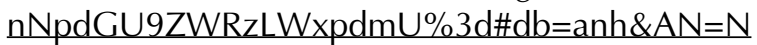
EM040311-71100C-0174

Tunmer, W., \& Greaney, K. (2010). Defining Dyslexia. Journal of Learning Disabilities, 43(3), 229-243.

Wearmouth, J., Glynn, T., \& Berryman, M. (2005). Perspectives on student behaviour in schools: Exploring theory and developing practice. London: Routledge.

Wheldall, K. (2000). Does rainbow repeated reading add value to an intensive literacy intervention programme for low-progress readers? An Experimental Evaluation. Educational Review, 52(1), 29-36.

\section{ACKNOWLEDGEMENT:}

The author would like to acknowledge S.

Macfarlane's (2006b in progress) A Critical Appraisal Process: He Anga Ta'tari in providing the foundation for undertaking this review of the Rainbow Reading programme.

\section{AUTHOR PROFILE}

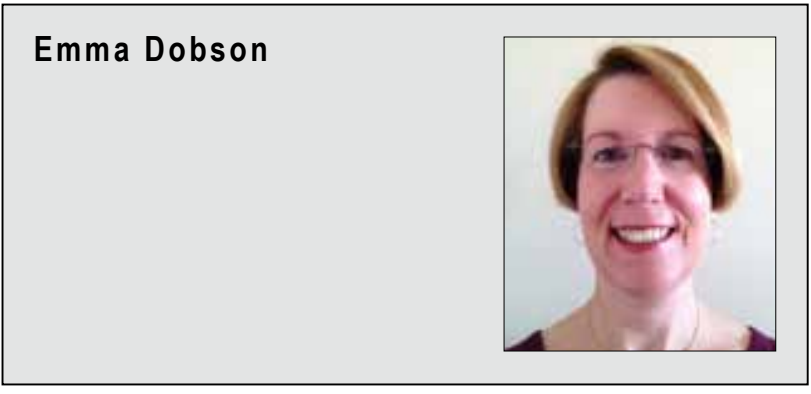

Emma Dobson is working as an RTLB Practice Leader in the Auckland West Cluster. She has recently completed the Postgraduate Diploma in Specialist Teaching (Learning and Behaviour) through Massey University, and also has a Master of Arts degree in Education. Emma's interests in the field of special education include evidence-based practice, inclusive education and interprofessional practice.

\section{Email:}

emma.dobson@donbuck.school.nz 